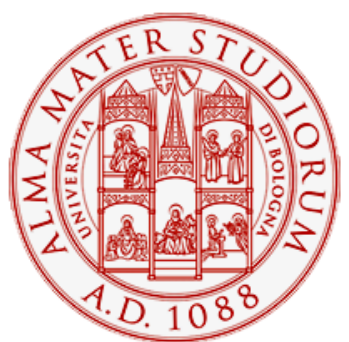

Alma Mater Studiorum - Università di Bologna DEPARTMENT OF ECONOMICS

On the Emergence of Overcompliance with Endogenous Environmental Standards and Patronising Consumers

Luca Lambertini

Alessandro Tampieri

Quaderni - Working Paper DSE $N^{\circ} 847$

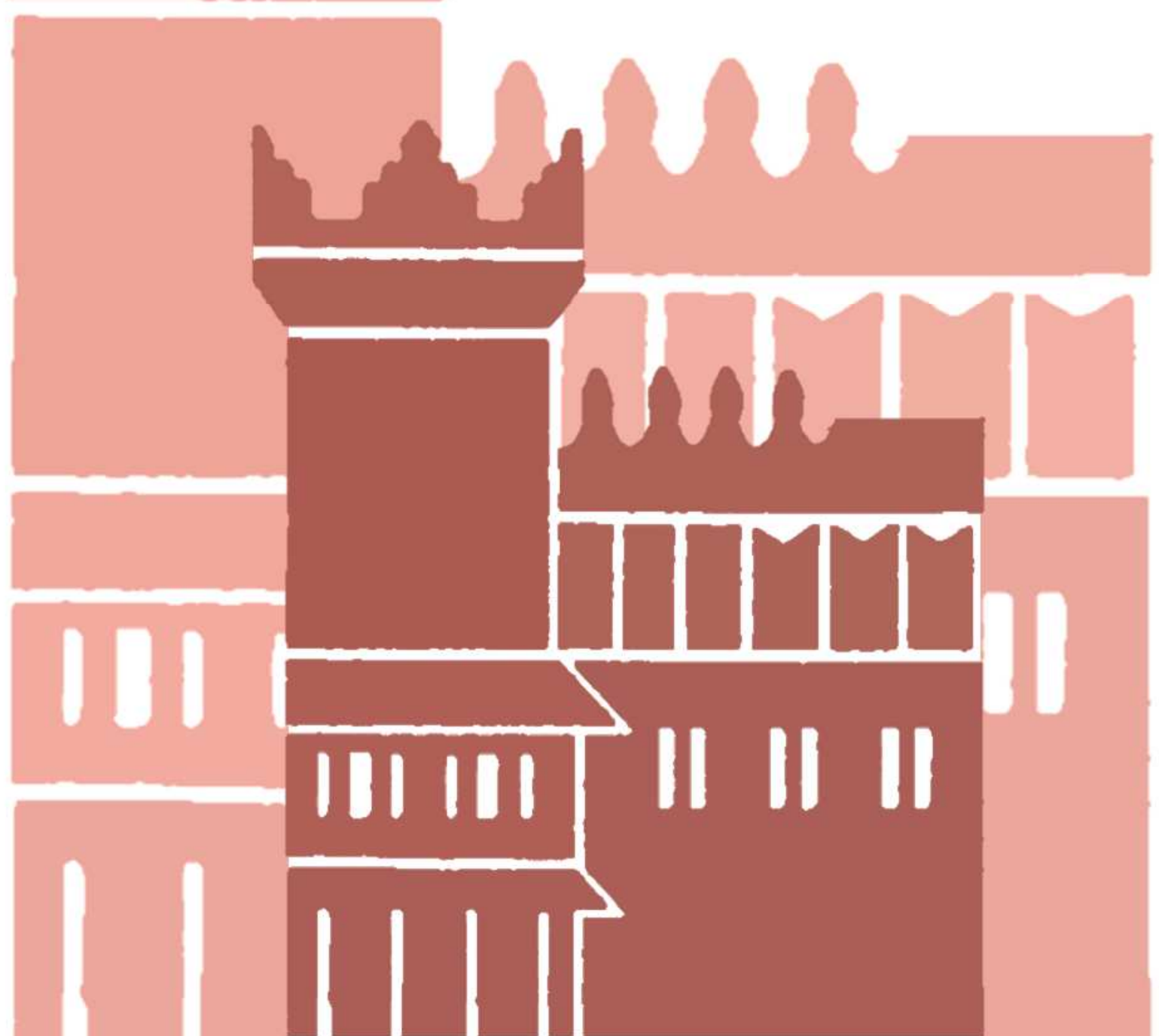




\title{
On the Emergence of Overcompliance with Endogenous Environmental Standards and Patronising Consumers
}

\author{
Luca Lambertini and Alessandro Tampieri*
}

September 5, 2012

\begin{abstract}
We propose a model of environmental overcompliance in a duopoly setting where consumers are environmentally concerned and may patronise the product they buy, firms set their green investment to abate the impact of productivity on pollution and a government sets the environmental standard with the aim to maximise welfare. We show that, with no patronising consumers, overcompliance is unilateral by the firm with higher quality standard under Bertrand behaviour, whereas both firms may overcomply under Cournot competition if the environmental impact of production is sufficiently low. Conversely with patronising consumers, overcompliance is unilateral with low environmental impact of production under price competition, and both firm overcomply under quantity competition.
\end{abstract}

JEL codes: L13, L51, Q50.

Keywords: environmental externality, patronising consumers.

*Department of Economics, University of Bologna, Strada Maggiore 45, 40125 Bologna, Italy; luca.lambertini@unibo.it; alessandro.tampieri@unibo.it. 


\section{Introduction}

Environmental overcompliance takes place when firms voluntarily conform to environmental standards higher than the ones required by the environmental regulation. There is a large evidence documenting the growing of environmental overcompliance (see Lyon and Maxwell, 2004 for a discussion).

The economic literature proposed several explanation of environmental overcompliance. One argument relies upon the assumption that consumers are environmentally concerned and thus they reward firms that overcomply by redirecting their demand towards them (Arora and Gangopadhyay 1995 (from now on, AG95), Bansal and Gangopadhyay, 2003, and Bagnoli and Watts, 2003, inter alia). Another explanation is that overcompliance has the aim to preempt the enactment of tighter regulation (Maxwell et al., 2000, and Lyon and Maxwell, 2003, inter alia). Finally, Denicolò (2008) suggests that a firm can overcomply to signal an uninformed government about low overcompliance costs and thus leading the government to require a tougher regulation. Here overcompliance has the purpose of raising rival's costs.

The present analysis nests in the approach related to the presence of green consumers. In particular, AG95 and Bansal and Gangopadhyay (2003) examine a vertically differentiated duopoly where firms sell a good differing in environmental quality (due to higher environmental production standards) and compete in prices. They show that overcompliance may emerge but

[i] the environmental standard is exogenously determined and thus not established through social welfare maximisation,

[ii] they do not consider the presence of the environmental externality (which in turn affects the endogenously-determined environmental standard) and

[iii] competition in quantities is not taken into account. 
In this paper we take the AG95's standpoint by considering the presence of an environmental externality, and endogenously setting the environmental standard through social welfare maximisation by the government. Further, we evaluate the introduction of an environmental standard with Cournot competition. Finally, we investigate the case in which consumers are green and "patronise" the good they choose to buy, i.e., they specifically care about the environmental impact of the good they buy.

Our results show that, with no patronising consumers, an environmental standard quality brings about unilateral overcompliance by the firm with higher quality standard under Bertrand behaviour, whereas both firms overcomply under Cournot competition if the environmental impact of production is sufficiently low. The result can be explained by the interaction between the price effect, that induces the two firms to increase environmental quality differentiation, and the environmental standard: the firm with lower environmental standard would lower its price (and thus its environmental quality) in order to acquire consumers that otherwise would not have bought the good, therefore the introduction of an environmental standard would induce an increase in quality. This may not happen under Cournot behaviour competition, since competition is softer and thus less differentiation occurs. Therefore the low-environmental-quality firm may set its quality above the standard. On the other hand, the firm with higher environmental quality raises its price (and quality) because of the price effect and by doing this it overcomplies.

Conversely, when we consider patronising consumers, overcompliance is unilateral if the environmental impact of production is sufficiently low and under Bertrand behaviour, and both firm overcomply under Cournot competition. Here the environmental quality contributes with the price effect to maximise profits. This because a consumer specifically cares about the pollution of the purchased good. Since a firm want to keep a relatively 
high environmental standard to please consumers, quality differentiation is smaller than the previous case, and this in turn increases the situation where overcompliance takes place.

The present analysis is similar to the literature on minimum quality standard in polluting industries, where the quality of goods is exclusively hedonic (see Lambertini and Tampieri (2012a) and Ecchia et al. (2011)). Papers that consider green consumers are also André et al. (2009) and Lambertini and Tampieri (2012b). Finally, Garcia-Gallego and Georgantzis (2009) assume green consumer in a duopoly setting where firms follow rules of Corporate Social Responsibility.

The remainder of the paper is organised as follows. Section 2 presents the model, Section 3 and 4 examine the results, both in price and quantity competition, with non-patronising and patronising consumers, respectively. Section 5 concludes.

\section{The model}

We consider a duopoly market for homogeneous products supplied by singleproduct firms. Production entails a negative environmental externality $s>0$. Firms can adopt a cleaning technology $q \in[0, Q]$ that reduces emissions, at a cost $c(q)$. We denote the firm that invests more in the cleaning technology and its competitor as $G$ and $B$, respectively, so that $q_{G}>q_{B}$. From now on, we will denote the good produced by firm $G$ as "green" and the good produced by firm $B$ as "brown".

The demand side is modelled à la Mussa and Rosen (1978). There is a continuum of consumers differing in the environmental concern, and the consumer types are identified by the index $\theta$, uniformly distributed with density equal to one in the interval $[0, \Theta]$ (thus total demand is equal to $\Theta)$. Parameter $\theta$ represents the consumers' marginal willingness to pay for a 
good produced according to green standards. Each consumer is assumed to buy at most one unit of the good in order to maximise the following surplus function:

$$
U=\theta q_{i}-p_{i},
$$

where $p_{i}$ is the market price at which that variety is supplied by firm $i=G, B$. Therefore, the consumer who is indifferent between $q_{G}$ and $q_{B}$ is identified by the level of marginal willingness to pay $\widehat{\theta}$ that solves

$$
\widehat{\theta} q_{G}-p_{G}=\widehat{\theta} q_{B}-p_{B}
$$

and therefore $\widehat{\theta}=\left(p_{G}-p_{B}\right) /\left(q_{G}-q_{B}\right)$. Thus, market demand for the green good is $x_{G}=\Theta-\widehat{\theta}$. We assume partial market coverage, so that there is another consumer, identified by $\widetilde{\theta}$, who is indifferent between buying $q_{B}$ or not buying at all:

$$
\widetilde{\theta} q_{B}-p_{B}=0,
$$

whereby $\widetilde{\theta}=p_{B} / q_{B}$ and the demand for the inferior variety is $x_{B}=\widehat{\theta}-\widetilde{\theta}$. Accordingly, we can define consumer surplus as follows:

$$
C S=\int_{\tilde{\theta}}^{\widehat{\theta}}\left(k q_{B}-p_{B}\right) d k+\int_{\widehat{\theta}}^{\Theta}\left(z q_{G}-p_{G}\right) d z .
$$

This is what one needs to use in order to model Bertrand behaviour, while inverse demands

$$
\begin{gathered}
p_{G}=\left(\Theta-x_{G}\right) q_{G}-q_{B} x_{B} \\
p_{B}=\left(\Theta-x_{G}-x_{B}\right) q_{B}
\end{gathered}
$$

are to be used under Cournot competition.

On the supply side, we denote as $\pi_{G}=p_{G} x_{G}-c_{G}\left(q_{G}\right)$ and $\pi_{B}=$ $p_{B} x_{B}-c_{B}\left(q_{B}\right)$ the profit functions of the green and brown-quality firm, respectively, where $c_{i}\left(q_{i}\right)>0, c_{i}^{\prime}, c_{i}^{\prime \prime}>0$ and the marginal cost of production is normalised to zero. Production entails a negative environmental externality $s=b\left(x_{G} / q_{G}+x_{B} / q_{B}\right)$, with $b>0$, measuring the negative impact of 
production on the environment. ${ }^{1}$ Social welfare is determined by the sum of profits and consumer surplus, minus the environmental externality:

$$
W=C S+\pi_{G}+\pi_{B}-s .
$$

It is important noting that the consumers' utility function can be modified by embedding the amount of pollution produced without changing any result. Indeed, with $U=\theta q_{i}-p_{i}-s$ would not modify the expressions of $\widehat{\theta}$ and $\tilde{\theta}$ resulting from $\widehat{\theta} q_{H}-p_{H}-s=\widehat{\theta} q_{L}-p_{L}-s$ and $\widetilde{\theta} q_{L}-p_{L}-s=-s$, respectively.

Competition takes place in two stages. In the first, firms choose the investment in environmental quality and in the second market competition takes place. Moves are simultaneous in both stages, and the solution concept is the subgame perfect equilibrium by backward induction. In what follows, we investigate separately an industry where price and quantity competition occurs, respectively.

\subsection{Price competition}

To begin with, the optimal prices for any given quality pair are:

$$
p_{G}^{N}=\frac{2 \Theta q_{G}\left(q_{G}-q_{B}\right)}{4 q_{G}-q_{B}} ; p_{B}^{N}=\frac{\Theta q_{B}\left(q_{G}-q_{B}\right)}{4 q_{G}-q_{B}},
$$

where the superscript $N$ stands for Nash equilibrium. The explicit derivation is omitted as it can be found in Ronnen (1991).

We now turn to the first stage in which environmental quality is chosen. We will prove our results by manipulating the set of the first order conditions in the two alternative cases under consideration, i.e., with or without the

\footnotetext{
${ }^{1}$ This modelisation of the environmental damage has been borrowed by Lutz et al. (2000).
} 
presence of an environmental standard. The relevant profit functions are:

$$
\begin{gathered}
\pi_{G}=\frac{4 \Theta^{2} q_{G}^{2}\left(q_{G}-q_{B}\right)}{\left(4 q_{G}-q_{B}\right)^{2}}-c_{G}\left(q_{G}\right) \\
\pi_{B}=\frac{\Theta^{2} q_{G} q_{B}\left(q_{G}-q_{B}\right)}{\left(4 q_{G}-q_{B}\right)^{2}}-c_{B}\left(q_{B}\right)
\end{gathered}
$$

With no environmental standard, the first order conditions for non cooperative profit maximisation are:

$$
\begin{gathered}
\frac{\partial \pi_{G}}{\partial q_{G}}=\frac{4 \Theta^{2} q_{G}\left(4 q_{G}^{2}-3 q_{G} q_{B}+2 q_{B}^{2}\right)}{\left(4 q_{G}-q_{B}\right)^{3}}-c_{G}^{\prime}\left(q_{G}\right)=0, \\
\frac{\partial \pi_{B}}{\partial q_{B}}=\frac{\Theta^{2} q_{G}^{2}\left(4 q_{G}-7 q_{B}\right)}{\left(4 q_{G}-q_{B}\right)^{3}}-c_{B}^{\prime}\left(q_{B}\right)=0 .
\end{gathered}
$$

We are now in a position to investigate how the investment in environmental quality is affected by the introduction of an environmental standard. To perform this task, we follow a procedure by now consolidated in the existing literature on minimum quality standards. In the regulated case, the government introduces an environmental standard aimed at affecting directly the behaviour of firm $B$. Firm $G$ 's FOC remains unchanged, while the regulator solves:

$$
\begin{gathered}
\frac{\partial W}{\partial q_{B}}=\frac{\Theta q_{H}^{2}\left[\Theta q_{G}^{2} q_{B}^{2}\left(20 q_{G}-17 q_{B}\right)+4 b\left(q_{G}-q_{B}\right)\left(4 q_{G}-q_{B}\right)\left(2 q_{G}+q_{B}\right)\right]}{2 q_{B}^{2}\left(4 q_{H}-q_{L}\right)^{3}} \\
-c_{B}^{\prime}\left(q_{B}\right)=0 .
\end{gathered}
$$

For any pair of generic qualities $\left(q_{G}, q_{B}\right)$, overcompliance from firm $G$ occurs once that the environmental regulation is binding (and therefore brings about an increase in both environmental qualities) if $\partial W / \partial q_{B}>\partial \pi_{B} / \partial q_{B}$. The presence of a negative externality implies that

$$
\operatorname{sign}\left\{\frac{\partial W}{\partial q_{B}}-\frac{\partial \pi_{L}}{\partial q_{B}}\right\}=\operatorname{sign}\left\{3 \Theta q_{G}^{2} q_{B}^{2}+4 b\left(q_{G}-q_{B}\right)\left(2 q_{G}+q_{B}\right)\right\}>0
$$


Note also that both firms' profits are positive for all

$$
c_{G}\left(q_{G}\right)<\frac{4 \Theta^{2} q_{G}^{2}\left(q_{G}-q_{B}\right)}{\left(4 q_{G}-q_{B}\right)^{2}}, c_{B}\left(q_{B}\right)<\frac{\Theta^{2} q_{G} q_{B}\left(q_{G}-q_{B}\right)}{\left(4 q_{G}-q_{B}\right)^{2}},
$$

and that

$$
\frac{4 \Theta^{2} q_{G}^{2}\left(q_{G}-q_{B}\right)}{\left(4 q_{G}-q_{B}\right)^{2}}-\frac{\Theta^{2} q_{G} q_{B}\left(q_{G}-q_{B}\right)}{\left(4 q_{G}-q_{B}\right)^{2}}=\frac{4 \Theta^{2} q_{G}\left(q_{G}-q_{B}\right)}{4 q_{G}-q_{B}}>0 .
$$

The foregoing discussion can be summarised in

Proposition 1 Under Bertrand behaviour an environmental standard quality brings about unilateral overcompliance by the firm with higher environmental standard.

Proposition 1 can be explained in the following way. Profit maximisation under Bertrand competition implies that firms strongly differentiate in prices (and thus in environmental quality) in order to increase the market coverage, i.e., firm $B$ sets its quality at a lower level to acquire consumers that otherwise would not have bought the good. Therefore the environmental standard is always above the quality level of firm $B$. Still for the competition effect, firm $G$ raises its environmental quality at a higher level than the environmental standard.

\subsection{Quantity competition}

In this section we investigate whether the introduction of environmental standard of production leads to overcompliance in an industry where firms compete in quantities. To begin with, we characterise optimal outputs for any given environmental quality pair:

$$
x_{G}^{N}=\frac{\Theta\left(2 q_{G}-q_{B}\right)}{4 q_{G}-q_{B}} ; x_{B}^{N}=\frac{\Theta q_{G}}{4 q_{G}-q_{B}}
$$


The explicit derivation of the Cournot equilibrium is omitted as it is known from Motta (1993).

We now turn to the first stage where the environmental game takes place. Like for price competition, we will prove our results by manipulating the set of the first order conditions. The relevant profit functions are:

$$
\begin{gathered}
\pi_{G}=\frac{\Theta^{2} q_{G}\left(2 q_{G}-q_{B}\right)^{2}}{\left(4 q_{G}-q_{B}\right)^{2}}-c_{G}\left(q_{G}\right) \\
\pi_{L}=\frac{\Theta^{2} q_{H}^{2} q_{L}}{\left(4 q_{H}-q_{L}\right)^{2}}-c_{B}\left(q_{L}\right)
\end{gathered}
$$

Without regulation of environmental quality, the first order conditions for non cooperative profit maximisation are:

$$
\begin{gathered}
\frac{\partial \pi_{G}}{\partial q_{G}}=\frac{\Theta^{2}\left(16 q_{G}^{3}-12 q_{G}^{2} q_{B}+4 q_{G} q_{B}^{2}-q_{B}^{3}\right)}{\left(4 q_{G}-q_{B}\right)^{3}}-c_{G}\left(q_{G}\right)=0, \\
\frac{\partial \pi_{B}}{\partial q_{B}}=\frac{\Theta^{2} q_{B}^{2}\left(4 q_{G}+q_{B}\right)}{\left(4 q_{G}-q_{L}\right)^{3}}-c_{B}\left(q_{B}\right)=0 .
\end{gathered}
$$

The optimal regulation of environmental quality requires solving the following:

$$
\frac{\partial W}{\partial q_{B}}=\frac{\Theta\left[\Theta q_{G}^{2} q_{B}^{2}\left(4 q_{G}+3 q_{B}\right)+4 b\left(8 q_{G}^{3}-6 q_{G}^{2} q_{B}+5 q_{G} q_{B}^{2}-q_{B}^{3}\right)\right]}{2\left(4 q_{G}-q_{B}\right)^{3} q_{B}^{2}}-c_{B}^{\prime}\left(q_{B}\right)=0 .
$$

For any pair of generic qualities $\left(q_{G}, q_{B}\right)$, the introduction of a minimum environmental standard leads firm $G$ to overcompliance if the environmental regulation is binding, i.e., if firm $B$ will raise its environmental quality in order to comply, because in turn this would lead firm $G$ to raise its environmental quality. This occurs if $\partial W / \partial q_{L}>\partial \pi_{L} / \partial q_{L}$. However, if the minimum environmental standard is not binding, this would imply that both firms are already overcomplying. By examining the sign of the difference $\partial W / \partial q_{L}-\partial \pi_{L} / \partial q_{L}$, we obtain

$$
\operatorname{sign}\left\{\frac{\partial W}{\partial q_{L}}-\frac{\partial \pi_{L}}{\partial q_{L}}\right\}=\operatorname{sign}\left\{8 b q_{G}^{2}-4 b q_{G} q_{B}+4 b q_{B}^{2}-\Theta q_{G}^{2} q_{B}^{2}\right\}
$$


whereby

$$
\frac{\partial W}{\partial q_{L}}>\frac{\partial \pi_{L}}{\partial q_{L}} \text { for all } b>\bar{b}=\frac{\Theta q_{G}^{2} q_{B}^{2}}{4\left(2 q_{G}^{2}-q_{G} q_{B}+q_{B}^{2}\right)},
$$

and conversely. Therefore, if $b$ is not large enough, both firms overcomply, whereas for $b$ sufficiently large, only firm $G$ overcomplies. Finally, note that both firms' profits are positive for all

$$
\begin{gathered}
c_{G}\left(q_{G}\right)<\frac{\Theta^{2}\left(16 q_{G}^{3}-12 q_{G}^{2} q_{B}+4 q_{G} q_{B}^{2}-q_{B}^{3}\right)}{\left(4 q_{G}-q_{B}\right)^{3}}, \\
c_{B}\left(q_{L}\right)<\frac{\Theta^{2} q_{H}^{2} q_{L}}{\left(4 q_{H}-q_{L}\right)^{2}}
\end{gathered}
$$

The foregoing discussion can be summarised in

Proposition 2 Under Cournot behaviour for $b<\bar{b}$, both firm overcomply to a environmental quality standard, and for $b>\bar{b}$ firm $G$ unilaterally overcomplies.

Under Cournot competition the incentive in overcompliance is stronger than in the Bertrand case. In particular, both firms overcomply if the marginal impact of production on pollution is sufficiently low. The intuition of this result can be spelled out as follows. Cournot competition is softer than Bertrand competition. The competition effect implies that it is not necessary for firm $B$ to lower the price (and therefore the environmental quality) as much as in the Bertrand case. If the marginal impact of pollution is sufficiently low, the competition effect is such that firm $B$ keeps the environmental quality higher than the socially optimal environmental standard. If conversely production has a strong impact on pollution, then the regulated environmental standard would set the environmental quality to a higher level than the one who maximises the private profit of the $B$ firm, because of the strong contraction of market coverage which in this case more than offset the competition effect aforementioned. 


\section{Patronising consumers}

In this section we analyse markets in which consumers specifically care for the pollution of the good they buy. We refer to them as "patronising" consumers as the specifically patronise the green quality of their purchased product. Unlike the previous scenario, in this case to consider the specific pollution of the good purchased in the utility function makes a difference according to the product quality. Therefore a consumer's utility function is now

$$
U=\theta q_{i}-p_{i}-b / q_{i}
$$

where $b / q_{i}$ is the individual pollution due to the production of the good purchased. Thus, the consumer who is indifferent between $q_{G}$ and $q_{B}$ is identified by the level of marginal willingness to pay $\widehat{\theta}$ that solves

$$
\widehat{\theta} q_{G}-p_{G}-b / q_{G}=\widehat{\theta} q_{B}-p_{B}-b / q_{B}
$$

and therefore

$$
\widehat{\theta}_{p}=\frac{q_{G} q_{B}\left(p_{G}-p_{B}\right)-b\left(q_{G}-q_{B}\right)}{q_{G} q_{B}\left(q_{G}-q_{B}\right)} .
$$

The consumer $\widetilde{\theta}_{p}$ who is indifferent between buying $q_{B}$ or not buying at all is:

$$
\widetilde{\theta}_{p} q_{B}-p_{B}-b / q_{B}=0
$$

whereby

$$
\widetilde{\theta}_{p}=\frac{p_{B} q_{B}+b}{q_{B}^{2}}
$$

Thus, market demand for the green and the brown good are $x_{G}=\Theta-\widehat{\theta}_{p}$ and $x_{B}=\widehat{\theta}_{p}-\widetilde{\theta}_{p}$. We now consider the exercise developed in Section 3 in the case of patronising consumers. 


\subsection{Price competition}

With price competition, the profits $\pi_{G}$ and $\pi_{B}$ in the second stage are:

$$
\begin{aligned}
\pi_{G} & =p_{G}\left[\Theta-\frac{q_{G} q_{B}\left(p_{G}-p_{B}\right)-b\left(q_{G}-q_{B}\right)}{q_{G} q_{B}\left(q_{G}-q_{B}\right)}\right]-c_{G}\left(q_{G}\right) \\
\pi_{B} & =\frac{p_{B}\left[q_{G} q_{B}\left(p_{G} q_{B}-p_{B} q_{G}\right)-b\left(q_{G}^{2}-q_{B}^{2}\right)\right]}{q_{G} q_{B}^{2}\left(q_{G}-q_{B}\right)}-c_{B}\left(q_{B}\right)
\end{aligned}
$$

Solving the FOCs w.r.t. prices yields:

$$
\begin{aligned}
p_{G}^{N} & =\frac{\left(q_{G}-q_{B}\right)\left[2 \Theta q_{G}^{2} q_{B}+b\left(q_{G}-q_{B}\right)\right]}{q_{G} q_{B}\left(4 q_{G}-q_{B}\right)}, \\
p_{B}^{N} & =\frac{\left(q_{G}-q_{B}\right)\left[2 \Theta q_{G} q_{B}^{2}+b\left(2 q_{G}-q_{B}\right)\right]}{q_{G} q_{B}\left(4 q_{G}-q_{B}\right)} .
\end{aligned}
$$

We now turn to the first stage in which environmental quality is chosen. With no environmental standard, the first order conditions for non cooperative profit maximisation are:

$$
\begin{gathered}
\frac{\partial \pi_{G}}{\partial q_{G}}=\frac{\Theta^{2} q_{G}^{4} q_{B}^{2}\left(4 q_{G}^{2}-3 q_{G} q_{B}+2 q_{B}^{2}\right)+24 b \Theta q_{G}^{3} q_{B}^{2}\left(q_{G}-q_{B}\right)}{q_{G}^{3} q_{B}^{2}\left(4 q_{G}-q_{B}\right)^{3}}- \\
\frac{\partial \pi_{B}\left(q_{G}-q_{B}\right)^{2}\left(4 q_{G}^{2}-15 q_{G} q_{B}+2 q_{B}^{2}\right)}{q_{G}^{3} q_{B}^{2}\left(4 q_{G}-q_{B}\right)^{3}}-c_{G}^{\prime}\left(q_{G}\right)=0 \\
\frac{\partial q_{B}}{q_{G} q_{B}\left(4 q_{G}-q_{B}\right)^{3}} \frac{\Theta^{2} q_{G}^{3} q_{B}^{4}\left(4 q_{G}-7 q_{B}\right)+2 b \Theta q_{G} q_{B}^{4}\left[8 q_{G}^{3}-6 q_{G} q_{B}\left(q_{G}-q_{B}\right)+q_{B}^{3}\right]}{q_{G}}- \\
\frac{b^{2}\left(48 q_{G}^{4}-20 q_{G}^{3} q_{B}-12 q_{G}^{2} q_{B}^{2}+9 q_{G} q_{B}^{3}+2 q_{B}^{4}\right)}{q_{G} q_{B}^{4}\left(4 q_{G}-q_{B}\right)^{3}}-c_{B}^{\prime}\left(q_{B}\right)=0 .
\end{gathered}
$$

In the regulated case, the regulator solves:

$$
\begin{aligned}
& \frac{\partial W}{\partial q_{B}}=\frac{\Theta^{2} q_{G}^{4} q_{B}^{4}\left(20 q_{G}-17 q_{B}\right)+2 b \Theta q_{G}^{2} q_{B}^{2}\left(16 q_{G}^{3}-12 q_{G}^{2} q_{B}+5 q_{B}^{3}\right)}{2 q_{G}^{2} q_{B}^{4}\left(4 q_{H}-q_{L}\right)^{3}}- \\
& \frac{b^{2}\left(144 q_{G}^{5}-36 q_{G}^{4} q_{B}-56 q_{G}^{3} q_{B}^{2}+33 q_{G}^{2} q_{B}^{3}-6 q_{G} q_{B}^{4}+2 q_{B}^{5}\right)}{2 q_{G}^{2} q_{B}^{4}\left(4 q_{H}-q_{L}\right)^{3}}-c_{B}^{\prime}\left(q_{B}\right)=0 .
\end{aligned}
$$


By examining the sign of the difference $\partial W / \partial q_{L}-\partial \pi_{L} / \partial q_{L}$, we obtain

$$
\begin{gathered}
\operatorname{sign}\left\{\frac{\partial W}{\partial q_{L}}-\frac{\partial \pi_{L}}{\partial q_{L}}\right\}=\operatorname{sign}\left\{6 b \Theta q_{G}^{2} q_{B}^{4}-3 \Theta^{2} q_{G}^{4} q_{B}^{4}+\right. \\
\left.b^{2}\left(12 q_{G}^{4}+4 q_{G}^{3} q_{B}-7 q_{G}^{2} q_{B}^{2}+2 q_{G} q_{B}^{3}-2 q_{B}^{4}\right)\right\}
\end{gathered}
$$

whereby

$$
\begin{gathered}
\frac{\partial W}{\partial q_{L}}>\frac{\partial \pi_{L}}{\partial q_{L}} \text { for all } \\
b<\widetilde{b}=\frac{3 \Theta q_{G}^{2} q_{B}^{2}}{3 q_{B}^{2}+\left[3\left(q_{G}+q_{B}\right)\left(12 q_{G}^{3}-8 q_{G}^{2} q_{B}+q_{G} q_{B}^{2}+q_{B}^{3}\right)\right]^{1 / 2}}
\end{gathered}
$$

and conversely.

The foregoing discussion can be summarised in

Proposition 3 Under Bertrand behaviour and patronising consumers, if $b>$ $\widetilde{b}$, both firm overcomply to a environmental quality standard, and if $b<\widetilde{b}$ firm $G$ unilaterally overcomplies.

Proposition 3 intuitively shows that, if a consumer specifically cares about the pollution of the purchased good and the marginal impact of production in pollution is sufficiently high, then both firms would increase the environmental quality level in order to increase the number of customers and thus their profits, irrespective of the socially optimal standard. Now indeed competition is not only related to price differences, like in the cases outlined in the previous section, but it is also related on keeping the environmental quality relatively high in order to satisfy the patronising customers, and this offsets the price effect for a high $b$. When $b$ is not so high instead, then the price effect is stronger and overcompliance is unilateral. 


\subsection{Quantity Competition}

With quantity competition, the profits $\pi_{G}$ and $\pi_{B}$ in the second stage are:

$$
\begin{gathered}
\pi_{G}=x_{G}\left[q_{G}\left(\Theta-x_{G}\right)-q_{B} x_{B}-\frac{b}{q_{G}}\right]-c_{G}\left(q_{G}\right) \\
\pi_{B}=\frac{x_{B}\left[q_{B}^{2}\left(\Theta-x_{G}-x_{B}\right)-b\right]}{q_{B}}-c_{B}\left(q_{B}\right)
\end{gathered}
$$

Solving the FOCs w.r.t. quantities yields:

$$
\begin{gathered}
x_{G}^{N}=\frac{\Theta q_{G} q_{B}\left(2 q_{G}-q_{B}\right)+b\left(q_{G}-2 q_{B}\right)}{q_{G} q_{B}\left(4 q_{G}-q_{B}\right)}, \\
x_{B}^{N}=\frac{\Theta q_{G}^{2} q_{B}^{2}-b\left(2 q_{G}^{2}-2 q_{B}\right)}{q_{G} q_{B}^{2}\left(4 q_{G}-q_{B}\right)} .
\end{gathered}
$$

In the first stage where the environmental game takes place and without regulation of environmental quality, the first order conditions for non cooperative profit maximisation are:

$$
\begin{gathered}
\frac{\partial \pi_{G}}{\partial q_{G}}=\frac{\Theta^{2} q_{G}^{2} q_{B}^{2}\left(16 q_{G}^{3}-12 q_{G}^{2} q_{B}+4 q_{G} q_{B}^{2}-q_{B}^{3}\right)+2 b \Theta q_{G}^{2} q_{B}^{2}\left(16 q_{G}-11 q_{B}\right)}{q_{G}^{2} q_{B}^{2}\left(4 q_{G}-q_{B}\right)^{3}}- \\
\frac{b^{2}\left(4 q_{G}^{3}-31 q_{G}^{2} q_{B}+48 q_{G} q_{B}^{2}+4 q_{B}^{3}\right)}{q_{G}^{2} q_{B}^{2}\left(4 q_{G}-q_{B}\right)^{3}}-c_{G}^{\prime}\left(q_{G}\right)=0, \\
\frac{\partial \pi_{B}}{\partial q_{B}}=\frac{\Theta^{2} q_{G}^{4} q_{B}^{4}\left(4 q_{G}+q_{B}\right)+2 b \Theta q_{G}^{2} q_{B}^{2}\left(8 q_{G}^{3}-6 q_{G}^{2} q_{B}+4 q_{G} q_{B}^{2}+q_{B}^{3}\right)}{q_{G}^{4} q_{B}^{4}\left(4 q_{G}-q_{B}\right)^{3}}- \\
\frac{b^{2}\left(48 q_{G}^{5}-20 q_{G}^{4} q_{B}-16 q_{G}^{3} q_{B}^{2}+12 q_{G}^{2} q_{B}^{3}-4 q_{G} q_{B}^{4}-q_{B}^{5}\right)}{q_{G}^{4} q_{B}^{4}\left(4 q_{G}-q_{B}\right)^{3}}-c_{B}^{\prime}\left(q_{B}\right)=0 .
\end{gathered}
$$

The optimal regulation of environmental quality requires solving the following:

$$
\begin{aligned}
& \frac{\partial W}{\partial q_{B}}=\frac{\Theta^{2} q_{G}^{4} q_{B}^{4}\left(4 q_{G}+3 q_{B}\right)+2 b \Theta q_{G}^{2} q_{B}^{2}\left(16 q_{G}^{3}-12 q_{G}^{2} q_{B}+12 q_{G} q_{B}^{2}+q_{B}^{3}\right)}{2 q_{G}^{2} q_{B}^{4}\left(4 q_{G}-q_{B}\right)^{3}}- \\
& \frac{b^{2}\left(144 q_{G}^{5}-68 q_{G}^{4} q_{B}-60 q_{G}^{3} q_{B}^{2}+48 q_{G}^{2} q_{B}^{3}-24 q_{G} q_{B}^{4}+q_{B}^{5}\right)}{q_{G}^{4} q_{B}^{4}\left(4 q_{G}-q_{B}\right)^{3}}-c_{B}^{\prime}\left(q_{B}\right)=0
\end{aligned}
$$


By examining the sign of the difference $\partial W / \partial q_{L}-\partial \pi_{L} / \partial q_{L}$, we obtain

$$
\begin{aligned}
& \operatorname{sign}\left\{\frac{\partial W}{\partial q_{L}}-\frac{\partial \pi_{L}}{\partial q_{L}}\right\}=\operatorname{sign}\left\{2 b \Theta q_{G}^{2} q_{B}^{4}-\Theta^{2} q_{G}^{4} q_{B}^{4}-\right. \\
& \left.b^{2}\left(12 q_{G}^{4}-4 q_{G}^{3} q_{B}-8 q_{G}^{2} q_{B}^{2}+4 q_{G} q_{B}^{3}-3 q_{B}^{4}\right)\right\}<0 .
\end{aligned}
$$

The foregoing discussion can be summarised in

Proposition 4 Under Cournot behaviour and patronising consumers both firm overcomply to a environmental quality standard.

The reason of this result is the same as for price competition, but now the effect of keeping a high environmental quality in order to acquire patronising consumers is stronger due to the softer competition under Cournot behaviour.

\section{Concluding remarks}

We have analysed a duopoly model of environmental overcompliance with green consumers and a government setting the environmental standard with the aim to maximise welfare. When consumers do not patronise the good they buy, unilateral overcompliance takes place under Bertrand behaviour, whereas both firms may overcomply under Cournot competition if the environmental impact of production is sufficiently low. On the other hand with patronising consumers, overcompliance is unilateral with low environmental impact of production under Bertrand competition, and both firm overcomply under Cournot behaviour. 


\section{References}

[1] André, F.J., González, P. and Porteiro, N. (2009). Strategic quality competition and the Porter hypothesis. Journal of Environmental conomics and Management 57: 182-194.

[2] Arora, S. and Gangopadhyay, S. 1995. Toward a theoretical model of voluntary overcompliance. Journal of Economic Behavior and Organization 28: 289-309.

[3] Bansal, S and Gangopadhyay, S. 2003. Tax/subsidy policies in the presence of environmentally aware consumers. Journal of Environmental Economics and Management 45: 333-355.

[4] Bulow, J., Geanakoplos, J. and Klemperer, P. (1985). Multimarket oligopoly: strategic substitutes and complements. Journal of Political Economy 93: 488-511.

[5] Crampes, C. and Hollander, A. 1995. Duopoly and quality standards. European Economic Review 39: 71-82.

[6] Denicolò, V. 2008. A signaling model of voluntary overcompliance. Journal of Economic Behavior and Organization 68: 293-303.

[7] Ecchia, G. and Lambertini, L. 1997. Minimum quality standards and collusion. Journal of Industrial Economics 45: 101-113.

[8] Ecchia, G., Lambertini, L. and Tampieri, A. Minimum quality standards in hedonic markets with environmental externalities. Environmental Modeling and Assessment (forthcoming).

[9] Garcia-Gallego, A. and Georgantzís, N. 2009. Market effects of changes in consumers' social responsibility. Journal of Economics and Management Strategy, 19: 453-487. 
[10] Lambertini, L. and Tampieri, A. 2012a. Do minimum quality standards bite in polluting industries? Research in Economics 66: 184-194.

[11] Lambertini, L. and Tampieri, A. 2012b. Vertical differentiation in a Cournot industry: The Porter hypothesis and beyond. Resource and Energy Economics 34: 374-380.

[12] Lombardini-Riipinen, C. 2005. Optimal tax policy under environmental quality competition. Environmental and Resource Economics 32: $317-$ 336.

[13] Lyon, T.P. and Maxwell, J.W. 2003. Self-regulation, taxation and public voluntary environmental agreements. Journal of Public Economics 87: 1453-1486.

[14] Lyon, T.P. and Maxwell, J.W., 2004. Corporate Environmentalism and Public Policy. Cambridge University Press, Cambridge.

[15] Lutz, S., Lyon, T. P. and Maxwell, J. W. 2000. Quality leadership when regulatory standards are forthcoming. Journal of Industrial Economics 48: $331-348$.

[16] Motta, M. (1993). Endogenous Quality Choice: Price vs. Quantity Competition. Journal of Industrial Economics 41: 113-131.

[17] Mussa, M. and Rosen, S. (1978). Monopoly and Product Quality. Journal of Economic Theory 18: 301-317.

[18] Ronnen, U. (1991). Minimum Quality Standards, Fixed Costs, and Competition. RAND Journal of Economics 22: 490-504.

[19] Valletti, T. (2000). Minimum Quality Standards Under Cournot Competition. Journal of Regulatory Economics 18: 235-245. 


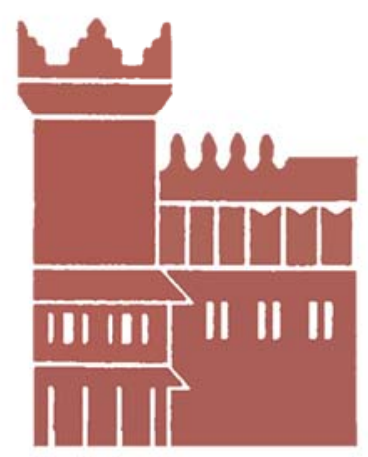

Alma Mater Studiorum - Università di Bologna DEPARTMENT OF ECONOMICS

Strada Maggiore 45

40125 Bologna - Italy

Tel. +39051 2092604

Fax +390512092664

http://www.dse.unibo.it 